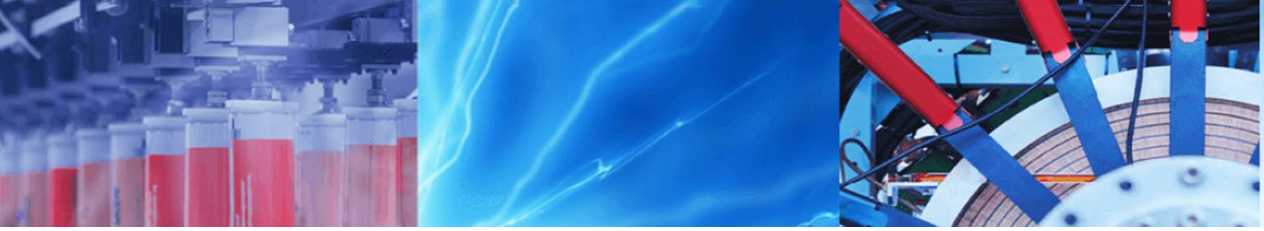

Research Article

\title{
Vertical stiffness of bicycle frame and its influence on rider comfort
}

\author{
Jinesh Shah ${ }^{1} \cdot$ Shivangi Shah ${ }^{1} \cdot$ Ghanshyam Mehta ${ }^{1} \cdot$ Jainam Gandhi ${ }^{1} \cdot$ Mehul Gor $^{1}$ (i)
}

Received: 29 February 2020 / Accepted: 23 August 2020 / Published online: 4 September 2020

(c) Springer Nature Switzerland AG 2020

\begin{abstract}
This study reports on relation between bicycle frame and rider comfort. It involves developing a theory on interdependence of vertical compliance or stiffness of bicycle frame and induced human comfort. The factors affecting vertical stiffness/compliance are identified and varied to observe their influence. A standard diamond type bicycle frame is modelled and analysed which is generally used for on-road bikes, applying different materials to the frame to note its deflection on application of load, considering the structural and material properties. The results of the analysis confirm with stiffness trend associated with Young's modulus of the material. i.e., for the same structure and loading conditions, material with lesser Young's modulus offer more compliance. Reducing thickness of tubing is also observed to be increasing compliance of the frame, which can be achieved either by reducing the outer diameter or increasing the inner diameter, the former being more beneficial according to manufacturing standpoint. This is verified by generating a series of supplementary equations. An experimental analysis is performed to discern the most influential tube out of every other tubings forming the frame structure, wherein their thicknesses are decreased by $10 \%$ one at a time, keeping the rest as it is. The study accomplishes that as compared to rest of the tubes, more rider comfort can be achieved by making least changes to the seat tube cross-sectional thickness, to decrease vertical stiffness and therefore, comfort. The obtained conclusions can serve as a base for further studies involving cyclist comfort and bicycle frame design.
\end{abstract}

Keywords Bicycle frame $\cdot$ Compliance $\cdot$ Rider comfort · Linear FEA

\section{Introduction}

Cycling is an eco-friendly mode of transport with added healthcare advantages, yet not preferred by many. This is due to unsatisfactory ride quality and rider discomfort. Understanding this concern lays the foundation of this research.

A survey involving 244 participants suggests that rider comfort is related to the bicycle components (tyres, wheel, fork, design and fitting of handlebars and saddle), the track and surrounding conditions.[1]. An experimental study shows that larger tyre sizes and lower tyre inflation pressure, reduces the impact of track unevenness [2]. Another study shows that an optimum stiffness of front suspension fork can suggestively reduce vibration transmission to the rider [3]. Bicycle fitting is of great significance since an adjustment such that the knees at the bottom of pedal stroke are slightly bent and arms are not overextended is expected to be a relaxed position for riding [4]. With a higher saddle (seat) and lower handlebar, force on palm and consequently, discomfort is observed to be high. Considering the rider physique and characteristics for deciding fitting adjustments can result into a more comfortable ride [5]. Saddle loading varies greatly with gender which becomes an important factor while designing a seat. Ischial tuberosity in females are spaced more than that of males, which makes wider saddles more preferable for women $[4,6]$.

\footnotetext{
$\triangle$ Mehul Gor, mehulgor@gcet.ac.in; Jinesh Shah, jineshshah0410@gmail.com; Shivangi Shah, shahshivangi14@gmail.com; Ghanshyam Mehta, mehtaghanshyam21@gmail.com; Jainam Gandhi, jainamgandhi0509@gmail.com | ${ }^{1}$ Mechanical Engineering Department, G H Patel College of Engineering and Technology, V.V.Nagar, Gujarat, India.
} 
A frame, being at the centre of bicycle assembly, is a significant part of human-bike interaction, henceforth, a notable stakeholder in rider comfort. Design and optimization of bicycle frame has since been an area of interest for various researchers considering distinct loading conditions, rider positions, ergonomics and human biomechanics. The frame must offer sufficient strength and stability with minimum weight to ease the riding experience. Material of the frame is, thus, selected [7]. Contemporary methods study bicycle frame behavior and stress concentration in different conditions and reinforce the frame with added material only in stress concentrated areas and dismiss unrequired material from rest of the frame, under safety limits [8]. Since frame geometry influences rider posture appreciably, it imperatively affects comfort. A study of cycling ergonomics shows that seat tube angles that are relatively steep $\left(80^{\circ}-90^{\circ}\right)$ provide a metabolic advantage by reducing oxygen requirement, heart rate and exertion compared to conventional seat tube angles $\left(\sim 70^{\circ}\right)$. This ultimately increases cyclist efficiency [9].

Various studies support that a bicycle with lesser weight to stiffness ratio performs better, and is hence preferred by manufacturers $[10,11]$. So forth, either the bicycle weight is decreased or stiffness is increased. Decreasing weight has a lower limit set as a frame too light would not sustain loads imposed by heavy riders, and can deviate readily owing to heavy wind loads while riding. So, increasing stiffness is mostly preferred. While laterally stiff frames provide stability and reduces dissipation of pedalling forces, thus transmitting power efficiently; vertically stiff frames tend to impart impact as-it-is to the rider, making the ride jolty and providing discomfort especially on uneven road surfaces. "Bicycling Science" by Wilson [11] is a comprehensive study of bicycle physics which discusses stiffness requirement as a design objective and supports larger vertical compliance in a frame.

Efforts have been made to optimize frame geometry, i.e. tube lengths and profiles provide an increase in vertical compliance and decrease in torsional flex [12, 13]. Modern developments, such as IsoSpeed by Trek Bicycle Corporation, provide for separating vertical stiffness and lateral stiffness of a frame in order to take advantage of vertical flex of the frame [14].

Research around vertical stiffness/ compliance of bicycle frame has an opening for further refinement. Authors have observed a lack of literature providing correlation between vertical stiffness and rider comfort. This research aims to bridge this gap and provide factors affecting it.

Following sections proceed to develop a qualitative study on vertical stiffness and rider comfort. Section 2 establishes a relation between vertical stiffness and rider comfort. Section 3 develops a bicycle frame model which is further used for analysis throughout the paper. Section 4 discusses parameters that influence vertical stiffness followed by an experimental analysis which aims to discover the most influential frame tube in regards with vertical stiffness in Sect. 5.

\section{Stiffness-comfort correlation}

This subsection discusses the contrast between the effect of force load and displacement load, justifies the type of load acting for a rider-bicycle and bicycle-road interaction and, correlates stiffness and comfort.

Every object when stressed deforms to a degree depending upon its material properties and structure [15]. A structure can be loaded in distinctive ways, either load can be applied or a displacement can be given [16]

In case (a) of Fig. 1, the beam is subjected to force $F$ and stress generated can be measured using,

$\sigma=\frac{F L C}{l}$

where $\mathrm{F}=$ applied load, $\mathrm{L}=$ distance from the fixed end where load is applied, $c=$ distance of extreme fibre from the neutral axis.

This is the most intuitive case and is to be considered while understanding rider-bike interaction as, the frame is subjected to loading when rider sits on the saddle, or peddles to move forward, or both.

In case (b), the beam undergoes displacement in accordance with the cam profile and so forth consequential stress and reaction forces are calculated [16].

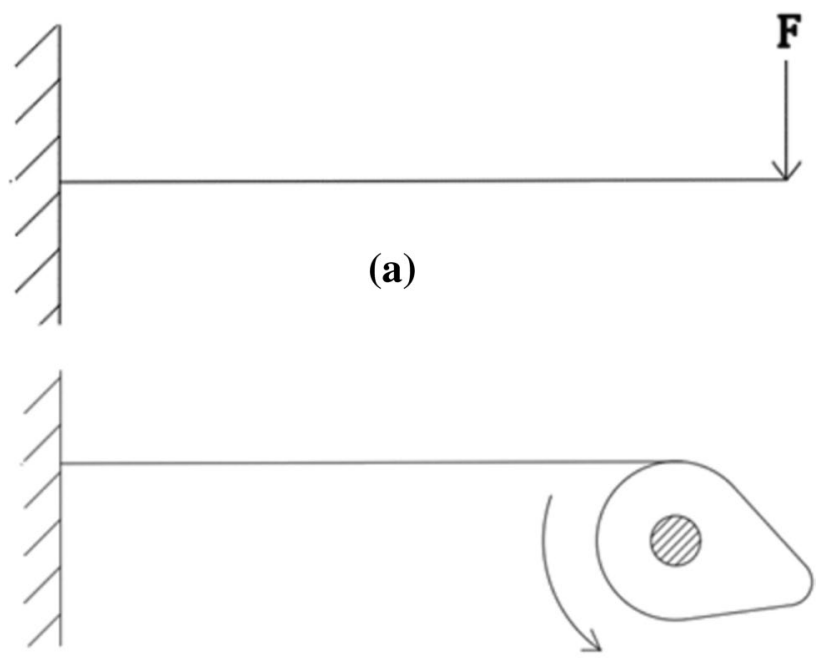

(b)

Fig. 1 Structure loaded by a applied load, b displacement 


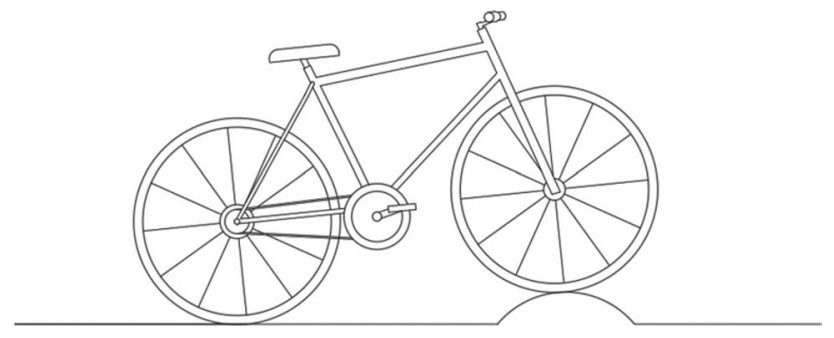

Fig. 2 Representation of road bump at front wheel

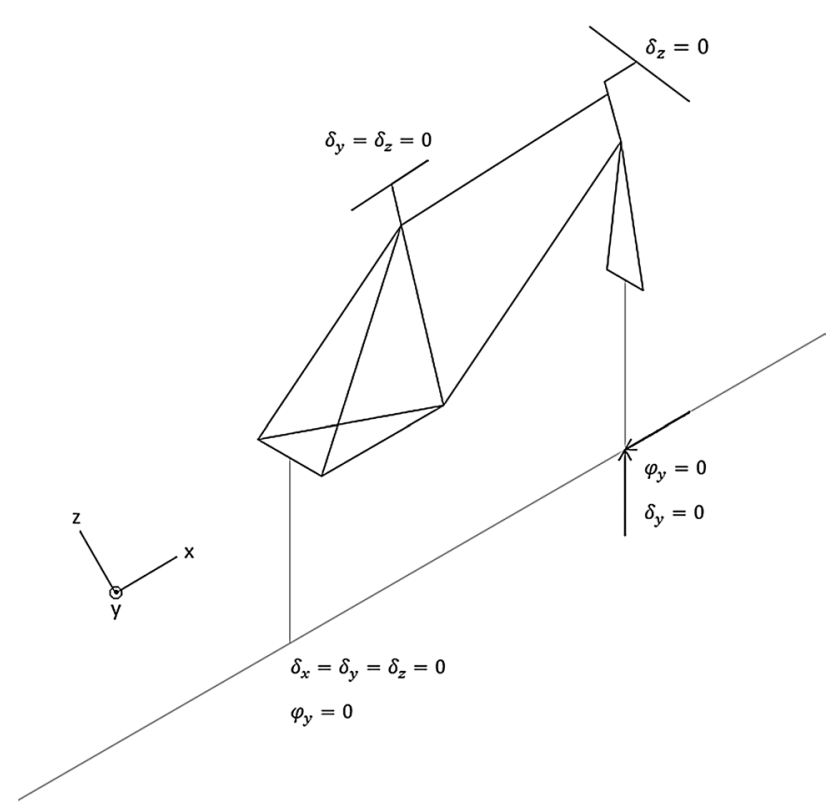

Fig. 3 Boundary conditions for a road bump at front wheel

$\delta=\frac{F L^{3}}{3 E I}$

where $F=$ applied load, $L=$ distance from the fixed end where displacement is applied, $E=$ Young's modulus, $I=$ Cross-sectional moment of inertia.

This case is considered for studying bicycle-track interaction. The track profile provides a displacement to the tires and subsequently to the frame structure, as shown in Fig. 2. The magnitude of this displacement is dependent on the contour of the terrain; an uneven road would impart more displacement than a smooth newly built road.

Figure 2 shows the case of road impact due to a road bump at front wheel and the position of a bicycle at the instant, when such discontinuities are to be faced by a bicycle frame. Road bump, here, serves as an example of such road discontinuities. Figure 3 provides the boundary conditions and obtained reaction forces. Linear motion about $y$ and $z$ axes is restricted at seat and about only $z$ axis for the handle bar. The rear hub has fixed end conditions, i.e. $\delta_{x}=\delta_{y}=\delta_{z}=0$ and rotation about $\mathrm{y}$ axis is restricted. At the front hub, experimentally obtained reaction forces $F_{x}$ and $F_{z}$ due to given displacement are shown $[17,18]$. This is similar to case (b) with the rear end being fixed and the front end undergoing deflection.

The required flexibility (i.e. inverse of stiffness) to allow a given deflection can be calculated as per Eq. 2 .

But, as the structure undergoes vertical bending, considering flexural stiffness for this case;

$K_{b}=\frac{3 E I}{L^{3}}$

where $\mathrm{C}=$ flexibility of the structure

$\therefore C=\frac{L^{3}}{3 E I}$

$\therefore K_{b}=\frac{F}{\delta}$ or $C=\frac{\delta}{F}$

Thus, as applied displacement increases, required compliance to permit it increases, i.e. the frame must be compliant enough to undergo the given displacement.

With increase in compliance of the structure, stiffness decreases, and the strain energy that can be stored in it increases [16]. Under the impact of a rough terrain, the frame stores the load due to impact in form of strain and this provides comfort to the rider. Lesser the stiffness of the frame, lesser will be the impact acting on the rider and more will be rider comfort.

\section{Modelling of bicycle frame}

In this section, a 3D solid bicycle frame model is developed. Modelling and Finite Element Analysis presented in this research is performed on Creo Parametric Version 5.0.4.0.

Commonly used nomenclature of bicycle frame is as shown in Fig. 4. Whereas, Fig. 5 shows the modelled diamond shaped bicycle frame for an on-road bicycle, in accordance with an idealised frame geometry mentioned by Cheng et al. [19].

Tube diameters used for the modelling are as mentioned in the Table 1.

\section{Methods and discussion}

Factors affecting vertical compliance of a bicycle frame are discussed in this section.

Stiffness of a line element is provided by [15] , 


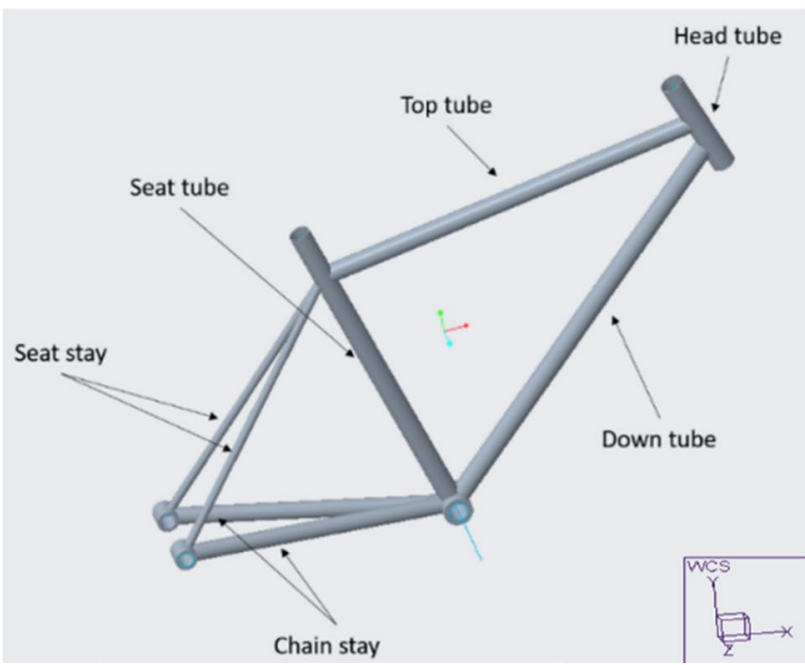

Fig. 4 Frame nomenclature

$K=\frac{F}{\delta}$

This relation holds true for a single link or a network of links forming a structure, as for a complex geometry of various elements, the relation can be expressed as, [16]

$\{f\}=[K]\{\delta\}$

where $[\mathrm{K}]=$ global stiffness matrix,$f=$ force vector,$\delta=$ displacement vector.
In this analysis, each link of bicycle frame is assumed to be a hollow tube that will behave as a link of circular cross-section under bending stresses due to conditions like rider sitting on the saddle, normal riding, or riding the bike without sitting on the saddle.

The flexural or bending stiffness of an entire bicycle frame structure in its elastic limit can be calculated by finding its deflection under a given load, which is obtained by double integration of differential equation of elastic line for a beam that bends in a plane of symmetry [20].

$E l v^{\prime \prime}=-M$

where $v=$ deflection of the beam at distance $x$ from origin, $v^{\prime \prime}=\frac{d^{2} v}{d x^{2}}, M=$ Bending moment, $E=$ Modulus of elasticity, $\mathrm{I}=$ cross-sectional moment of inertia.

The sign of the equation is chosen in consistency with the selected coordinate axes.

$K_{b}=c \times \frac{E I}{L^{3}}$

$K_{b} \alpha \frac{E l}{L^{3}}$

where $\mathrm{c}=$ dimensionless constant depending upon end conditions and type of load.

For instance, bending stiffness of a cantilever beam with load applied at the free end is given by,

Fig. 5 Frame geometry

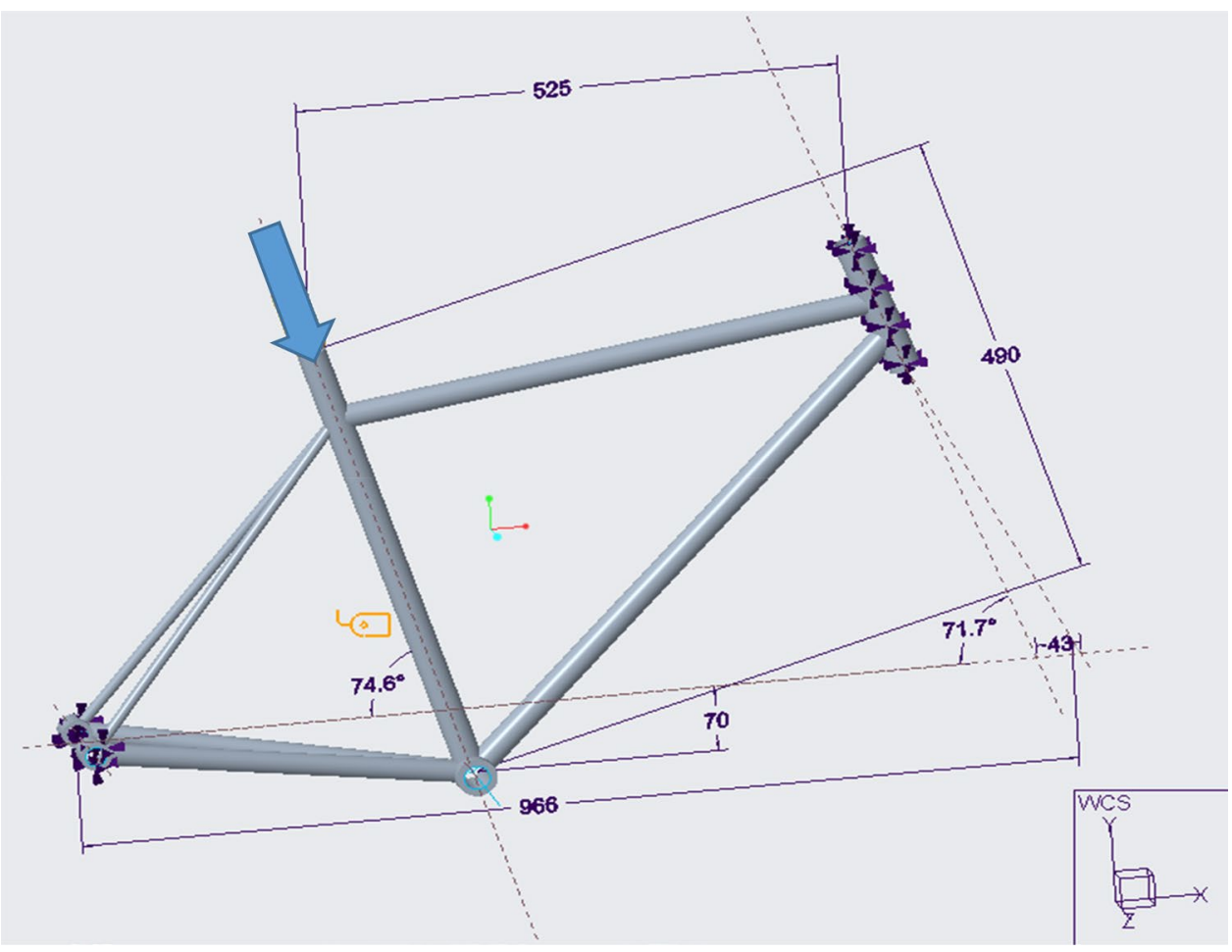


Table 1 Tube cross-sectional dimensions

\begin{tabular}{lll}
\hline Member & $\begin{array}{l}\text { Major diameter } \\
\text { Minor diameter } \\
(\mathrm{mm})\end{array}$ & Thickness $(\mathrm{mm})$ \\
\hline Seat tube & 28.6 & 0.9 \\
Top tube & 26.8 & \\
& 25.4 & 0.7 \\
Down/bottom tube & 24 & \\
& 26.6 & 0.9 \\
Head tube & 24.8 & 0.9 \\
& 31.75 & \\
Front fork & 29.95 & 1.18 \\
& 14.18 & \\
Chain stay & 11.82 & 0.79 \\
Seat stay & 23.1 & \\
& 21.52 & 1.27 \\
\hline
\end{tabular}

$K_{b}=\frac{3 E I}{L^{3}}$

Thus, $\mathrm{c}=3$ for this case.

While, for load applied at the centre of a simply supported beam $c=48$ and bending stiffness is provided by [15],

$K_{b}=\frac{48 E I}{L^{3}}$

The value of bending stiffness for various types of beam structures have different values of constants ' $c$ ' in their equation but the deciding parameters stay the same: end conditions of the beam, the kind of load applied, and the distance of application of load from the ends.

Therefore, flexural or bending stiffness $K_{b}$ is a function of inner diameter, outer diameter and henceforward, the thickness $t=\frac{D-d}{2}$ of the circular hollow cross-section of the element.

where $\mathrm{E}=$ Young's modulus of the material, $\mathrm{l}=$ crosssectional moment of inertia $=\frac{\pi\left(D^{4}-d^{4}\right)}{64}, A=$ cross-sectional area $=\frac{\pi\left(D^{2}-d^{2}\right)}{4}, L=$ length of beam, $D=$ outside diameter of cross-section, $d=$ inside diameter of cross-section.

By varying material, diameters $D$ and $d$, or thickness $t$, stiffness of each tube can be varied, thus changing the overall stiffness of the structure. Hence, the methods used to vary the stiffness are changing material and/or changing thickness.

\subsection{Changing material}

In this sub-section a static linear FEA is performed to observe the deflection of frame about $Y$-axis (vertical deflection) for different materials, which would indicate its vertical compliance. More deflection would signify larger compliance.

Tubing of only circular cross-section and modelled geometry is considered, to concentrate up on the influence of material and material properties on vertical compliance. Although loading condition during cycling can be complex, a simple vertically downward force is applied on the seat tube, i.e. simple bending method of loading. This simplifies the analysis, since the focus is to only compare materials on the basis of their deflection under applied load. Loading conditions and constraints are provided as per [21] for measurement of vertical stiffness i.e. Load $=2500 \mathrm{~N}$ at the top of the seat tube and, fixed constraints at the front and the rear hub. Position of load can be marked in Fig. 5 .

The materials and their properties taken into consideration for analysing frame stiffness used by leading bicycle frame manufacturing brands are as shown in Table 2 [11].

The scale provided separately for each case in the Fig. $6 a-c$, represents minimum to maximum deflection in $y$-direction, from bottom to top, blue to red.

For the same structure and loading conditions, stiffness is majorly dependent on the material as per Eq. (7). Since Young's modulus of a material is a measure of stiffness, it is the deciding factor.

The analysis as per Fig. 6 clearly shows that Aluminium 6061 deflects the most which is also confirmed by the value of Young's modulus [15]. Lesser value offers lower stiffness and more compliance

\subsection{Changing thickness}

This subsection develops models for varying thickness of tubing and perceive the most advantageous one out of them. Thickness of tubing can be reduced by (i) reducing outer diameter (keeping the inner diameter unchanged); (ii) increasing inner diameter (keeping outer diameter

Table 2 Material properties

\begin{tabular}{lllll}
\hline Material & $\begin{array}{l}\text { Tensile ultimate } \\
\text { stress (MPa) }\end{array}$ & $\begin{array}{l}\text { Tensile yield } \\
\text { stress (MPa) }\end{array}$ & $\begin{array}{l}\text { Young's modulus } \\
(\mathrm{GPa})\end{array}$ & Poisson's ratio \\
\hline Aluminium 6016 & 68.9 & 276 & 72 & 0.3 \\
Medium carbon steel & 520 & 435 & 207 & 0.29 \\
Titanium & 1000 & 990 & 114 & 0.33 \\
\hline
\end{tabular}




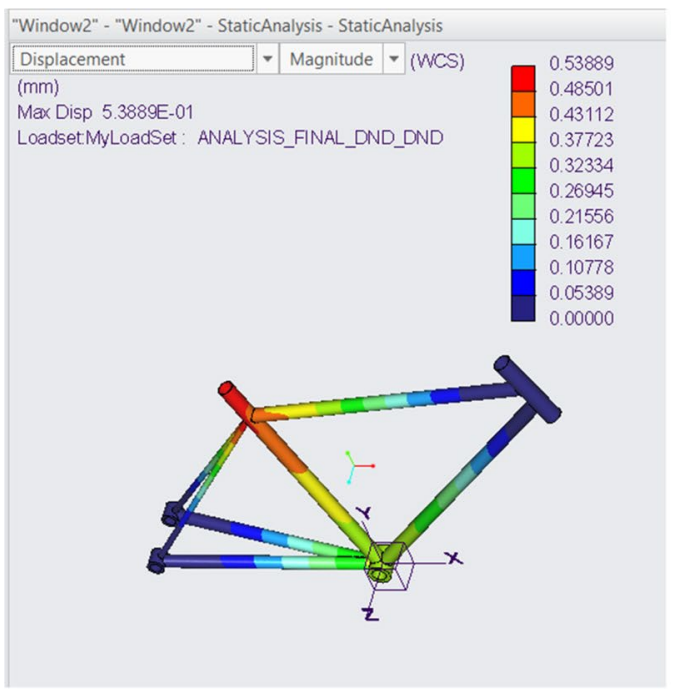

(a) Aluminium 6061

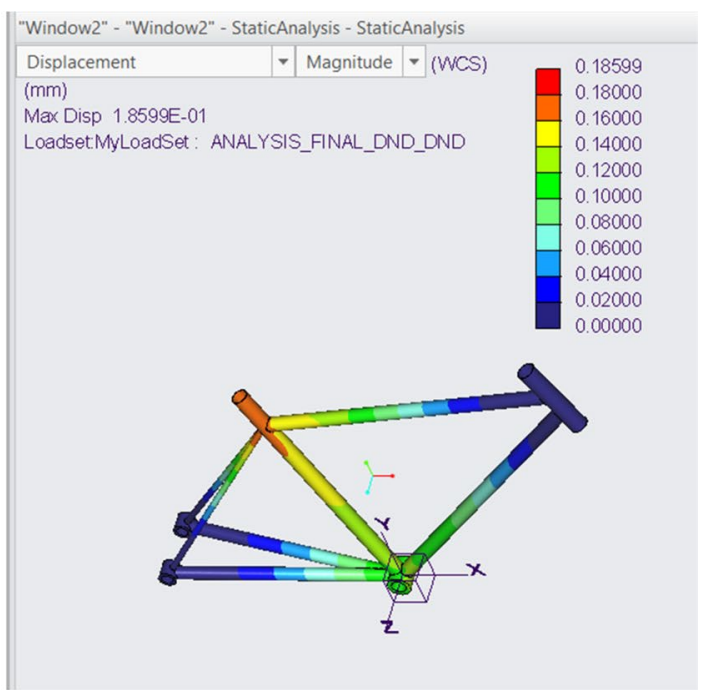

(b) Medium carbon steel

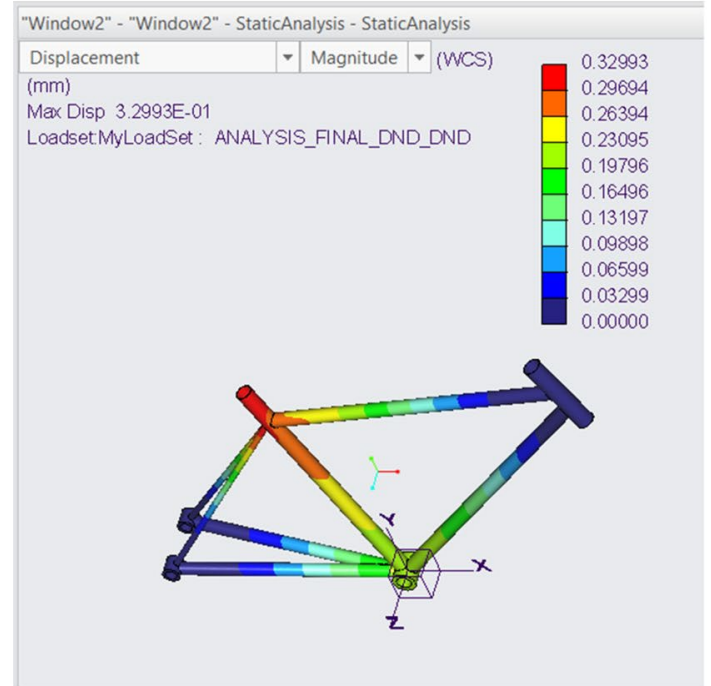

(c) Titanium

Fig. 6 Analysis for different materials

unchanged); or (iii) changing both the diameters simultaneously. For simplicity of analysis, only case (i) and (ii) are evaluated.

As mentioned earlier, stiffness is dependent on crosssectional moment of inertia I,

$$
\begin{aligned}
I=\frac{\pi\left(D^{4}-d^{4}\right)}{64} & =\frac{\pi(D-d)(D+d)\left(D^{2}+d^{2}\right)}{64} \\
& =\frac{\pi(2 t)(D+d)\left(D^{2}+d^{2}\right)}{64}
\end{aligned}
$$

where $D=$ Outer Diameter, $d=$ Inner Diameter, $t=$ Thickness $=(D-d) / 2$.

\section{SN Applied Sciences}

For both the cases, desired thickness is kept the same. Thus, the deciding factor is

$(D+d)\left(D^{2}+d^{2}\right)$

For Fig. 7a Case (i), D is decreased by $2 x$ (say) such that $D<2 x<D-d$

Thus the thickness becomes $(t-x)$, And $(D+d)\left(D^{2}+d^{2}\right)$ becomes, 
Fig. 7 a Case (i) reduction in outer diameter. $\mathbf{b}$ Case (ii) Increase in inner diameter
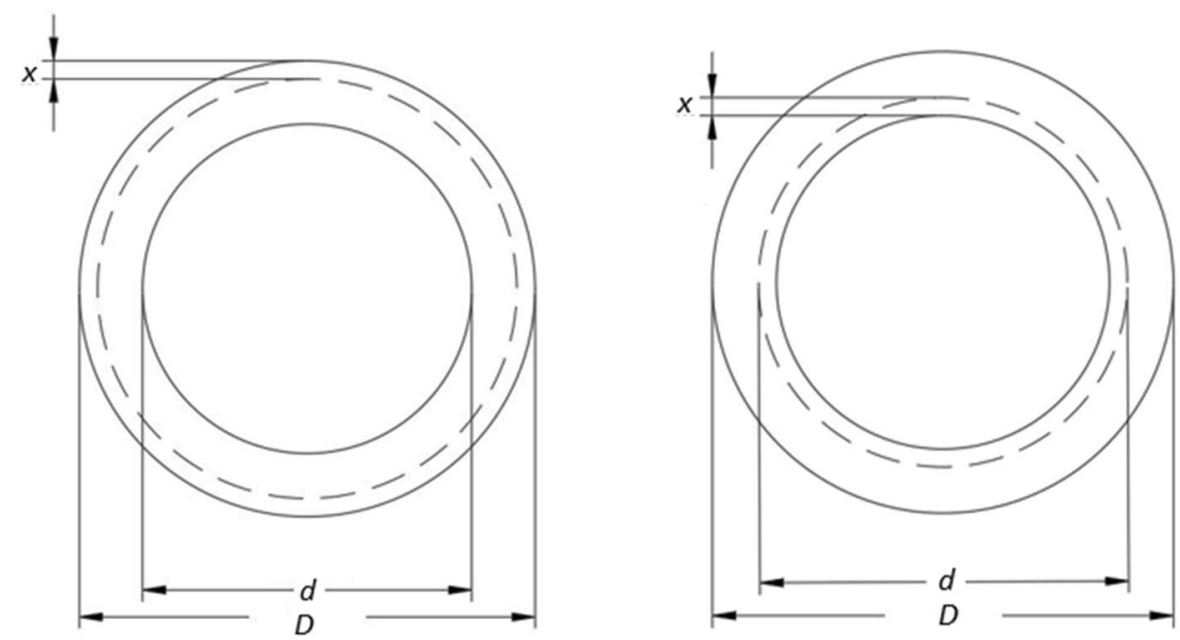

(a) Case (i) Reduction in outer diameter

(b) Case (ii) Increase in inner diameter
$(D+d-x)\left((D-x)^{2}+d^{2}\right)$

$\therefore I^{\prime}=\frac{\pi(2)(t-x)(D+d-x)\left((D-x)^{2}+d^{2}\right)}{64}$

While, in case Fig. 7b case (ii), consider $d$ to be increasing by same amount $2 x$,

Thus thickness $t$ becomes $(t-x)$, and the term $(D+d)\left(D^{2}+d^{2}\right)$ becomes $(D+d+x)\left(D^{2}+(d+x)^{2}\right)$

$\therefore I^{\prime \prime}=\frac{\pi(2)(t-x)(D+d-x)\left(D^{2}+(d+x)^{2}\right)}{64}$

Since, $t, x, D, d>0$, by Eqs. (10) and (11)

$\therefore I^{\prime}<I^{\prime \prime}$

i.e., for the same thickness, cross-sectional moment of inertia of case (i) is less than that of case (ii), which in turn provides more compliance (inverse of stiffness) in case (i) for the same reduction in thickness.

The requirement of material will also be different in both the cases as it depends on the volume of the tube.

For a tube, its volume is given by,

$V=\pi\left(R^{2}-r^{2}\right) I$

where $\mathrm{R}=$ outer diameter, $\mathrm{r}=$ inner diameter, $\mathrm{I}=$ length of the tube.

For case (i), the volume becomes

$$
\begin{aligned}
V^{\prime} & =\pi\left((R-x)^{2}-r^{2}\right) I \\
& =\pi\left(R^{2}-r^{2}-2 x R+x^{2}\right) I
\end{aligned}
$$

For case (ii), volume is given by,

$$
\begin{aligned}
V^{\prime \prime} & =\pi\left(R^{2}-(r+x)^{2}\right) I \\
& =\pi\left(R^{2}-r^{2}+2 x r-x^{2}\right) I
\end{aligned}
$$

Thus volume in both these cases is different for the same thickness.

To set a comparison, an assumption is made that volume in case (i) is less than that in case (ii).

From Eqs. (13) and (14),

$\therefore \pi\left(R^{2}-r^{2}-2 x R+x^{2}\right) l<\pi\left(R^{2}-r^{2}+2 x r-x^{2}\right)$

$\therefore R^{2}-r^{2}-2 x R+x^{2}<R^{2}-r^{2}+2 x R-x^{2}$

To hold this true, $x^{2}-2 x R<2 x r-x^{2}$ must be true.

$\therefore x^{2}-2 x R<2 x r-x^{2}$

$\therefore x<R+r$

By the basic condition for $x$, Eq. (9):

$r<x<R-r$

$\therefore x<R-r<R+r$

$\therefore x<R+r$

Thus, Eq. (15) holds true. Therefore, the assumption is correct indicating that volume, and thus the material required, in case (i) is less than that in case (ii), which shows that according to manufacturing standpoint, case (i) is better. Thus, this result can prove to be of 
importance for sports equipment manufacturing industries since it cuts down on material requirement for the required compliance of a frame.

\section{Deflection analysis of frame tubing}

Based upon discussed case of varying stiffness by varying thickness of tubing (Sect. 4.2), an analysis is performed wherein thickness of various tubes of the frame is decreased, singly. Thickness of each tube is decreased by $10 \%$ (by decreasing the outer diameter of the tube keeping inner diameter constant).

This analysis will observe cross-sectional dimensions of which tube contributes the stiffness and rider comfort. The tubes taken into consideration are as follows:

- Seat stay.

- Chain stay.

- Seat tube.

- Bottom tube.

- Top tube.

Material and frame geometry is kept same for each case to isolate and focus on the influence of each tube on compliance, individually. The loading condition employed is identical to that used in Sect. 4.1, since the motive of this analysis is to observe deflection in various cases only.

The front and the rear hub were considered fixed during the analysis and point load is applied on the seat tube (shown in Fig. 6).

The failure theory used in this static linear analysis is maximum shear stress theory as the material used is Aluminium 6061 which is a ductile material. It's applied properties as per Table 2.

Figure 8a-e shows the performed deflection analysis, while Fig. 9a-e shows failure indices for each case.

In Fig. 8, a scale representing minimum to maximum deflection, from bottom to top, blue to red, is provided for each case separately. In Fig. 9, failure index of the structure is provided on a scale. It can be noted that in each case, failure index obtained is fairly below 1 , thus these cases are safe and do not fail or buckle under applied loading condition.

In accordance with the scale in Fig. 8, minimum deflection is observed at the head tube and the rear hub, owing to fixed end conditions. While a moderate deflection can be seen at the bottom bracket of the frame, the top of the seat tube undergoes the most deflection for each case, but in particular, its maximum deflection is observed for Fig. 8 case (c). In case (c), cross-sectional thickness of seat tube is reduced with thickness of other tubes intact, which results in maximum deflection; indicating that frame stiffness reduces the most for the same percentage reduction in thickness of seat tube, out of all 5 tubes under consideration in each case. This infers that out of all the links of a frame, seat tube will require minimum change in thickness to provide same desired compliance, thus influencing frame stiffness and rider comfort the most.

Seat tube is followed by bottom tube (Fig. 8 case (d)), proving to be $2^{\text {nd }}$ most influencing link of a bicycle frame in regards with compliance. For Chain stay (Fig. 8 case (b)) and Top tube (Fig. 8 case (e)), deflection is nearly equal, which shows that changing dimensions of any of the two will have similar contribution in changing overall stiffness of the frame. Whereas, Fig. 8. Case (a) shows the least overall deflection, providing that seat stay has the least effect on frame stiffness.

The data analysed along with the results obtained are mentioned in Table 3.

\section{Conclusion}

Rider comfort is the major concern in cycling. Vertical stiffness of a bicycle frame is correlated with rider comfort. This research provides a theory to support this hypothesis and concludes that less vertical stiffness, i.e., more vertical compliance provides more cyclist comfort. Major findings of conducted research are:

1. Vertical stiffness of the frame depends mainly on material and cross-sectional dimensions of tubing. Upon applying various materials to the modelled frame and performing linear FEA, considering factors such as frame geometry and material properties, it can be concluded that for better rider comfort, Aluminium 6061 will be a superior choice, in comparison to Medium Carbon Steel and Titanium.

2. Maximum deflection is obtained by changing seat tube cross-sectional thickness, in comparison to all other tubing as shown in Table 3. This provides more compliance and hence better rider comfort.

3. For the same desired change in stiffness of the frame tubing, the methods employed i.e., changing outer diameter with inner diameter unchanged and vice versa will have inconsistent effects, former being beneficial according to manufacturing stand-point.

The proposed research adds to the literature around stiffness of a bicycle frame and can be of importance while designing a bicycle.

Reducing stiffness can provide rider comfort, but reducing it extensively might have few downsides. Hence, setting a limit to reducing stiffness is a future scope of research. This study is limited to a circular cross-sectional 


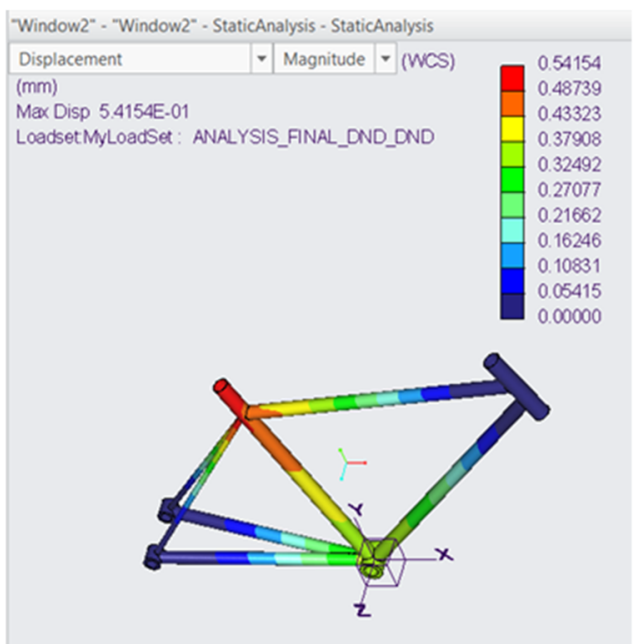

(a)

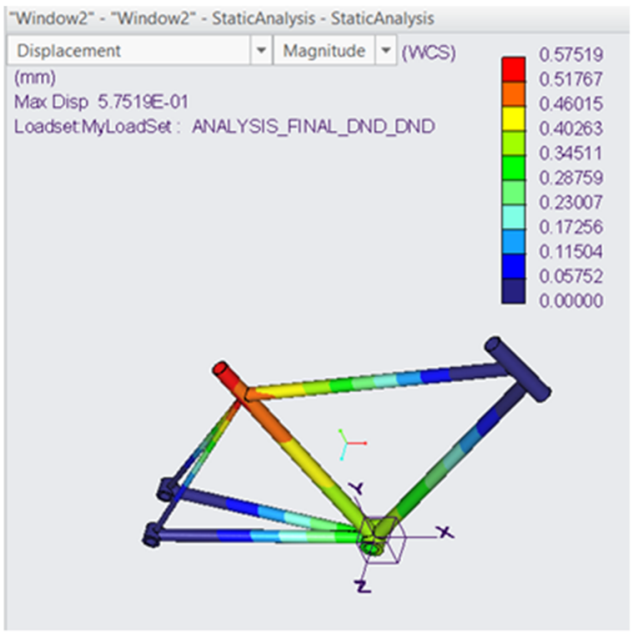

(c)

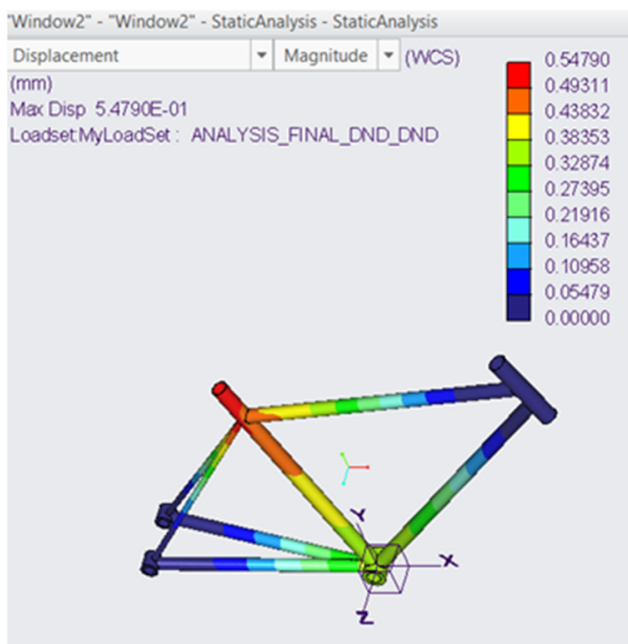

(b)

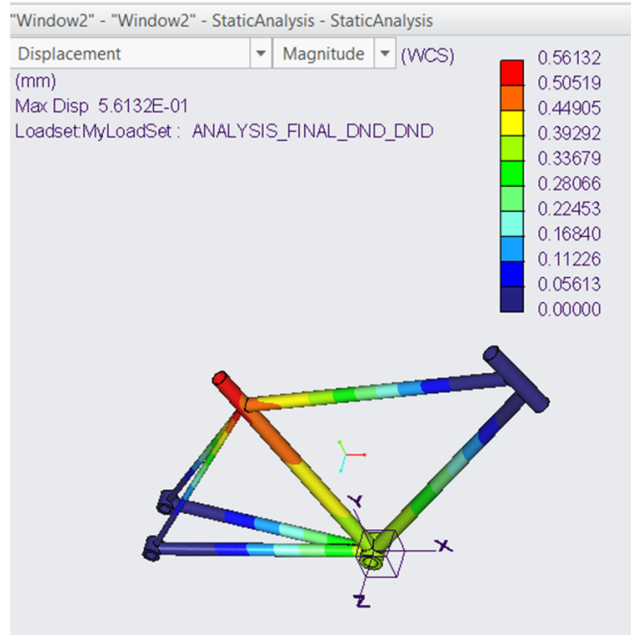

(d)

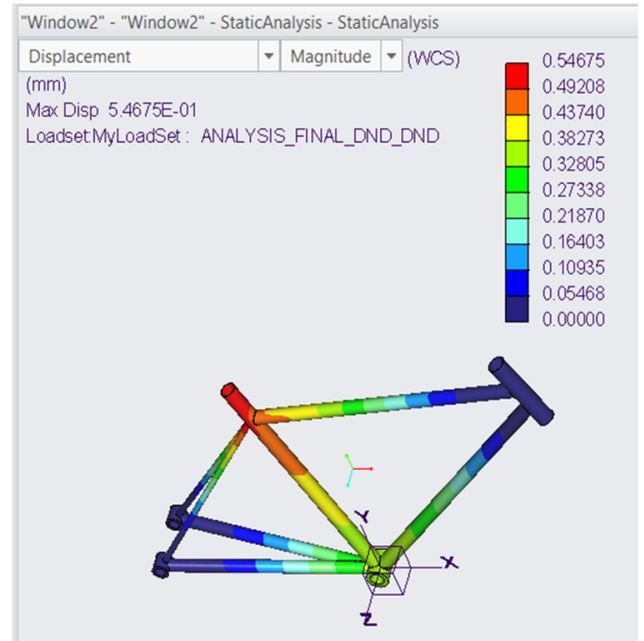

(e)

Fig. 8 a Seat stay. b Chain stay. c Seat tube. d Bottom tube. e Top tube 


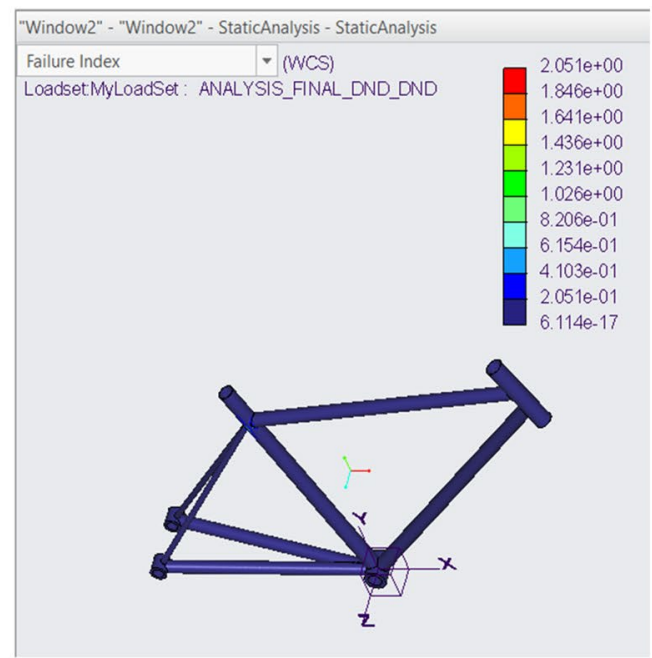

(a)

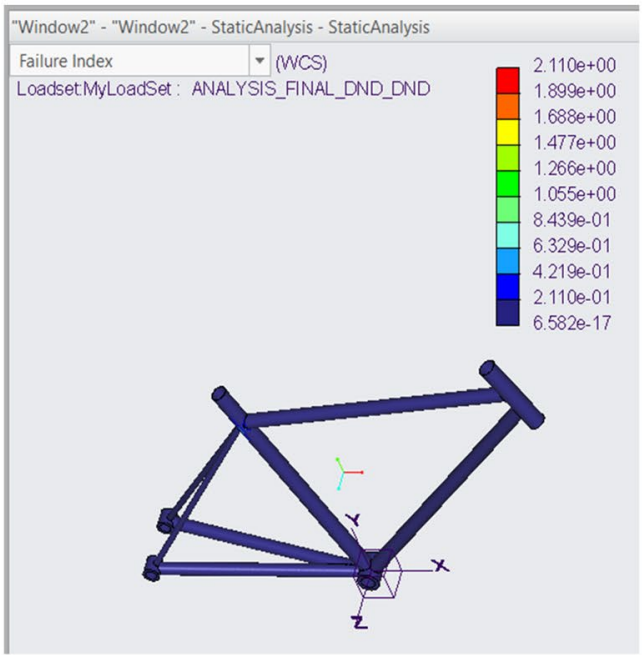

(c)

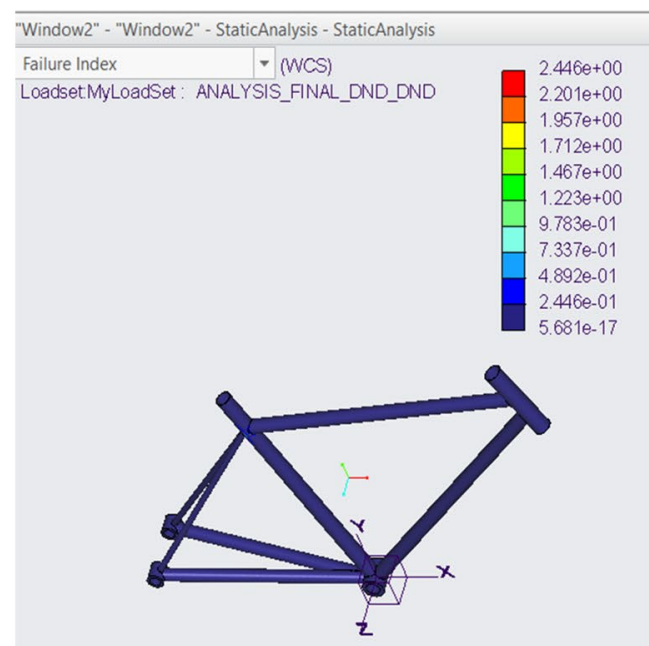

(b)

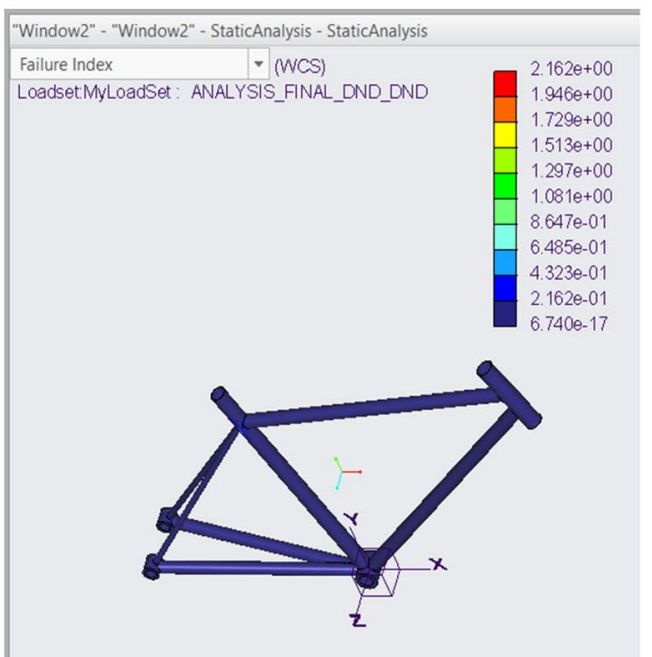

(d)

"Window2" - "Window2" - StaticAnalysis - StaticAnalysis

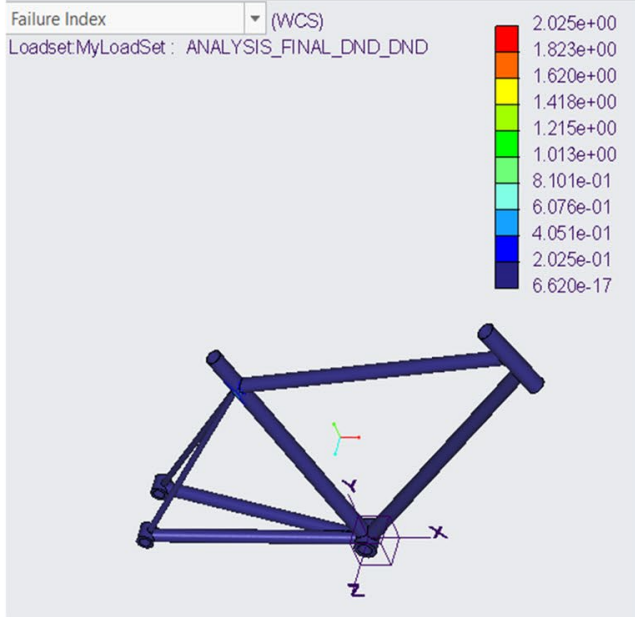

(e)

Fig. 9 a Seat stay. b Seat tube. c Chain stay. $\mathbf{d}$ Bottom tube. e Top tube

\section{SN Applied Sciences}


Table 3 Results obtained

\begin{tabular}{llllllll}
\hline Case & Tube & $\begin{array}{l}\text { Outer diam- } \\
\text { eter } d_{o}\end{array}$ & Inner diameter $d_{i}$ & $\begin{array}{l}\text { Initial thick- } \\
\text { ness } t_{i}\end{array}$ & Final thickness $t_{f}$ & $\begin{array}{l}\text { Change in thick- } \\
\text { ness } \Delta t\end{array}$ & $\begin{array}{l}\text { Maximum } \\
\text { deflection }\end{array}$ \\
\hline a & Seat stay & 11.3 & 8.76 & 1.27 & 1.143 & 0.127 & 0.54140 \\
b & Chain stay & 23.1 & 21.52 & 0.79 & 0.711 & 0.079 & 0.54705 \\
c & Seat tube & 28.6 & 26.8 & 0.9 & 0.81 & 0.09 & 0.57582 \\
d & Bottom tube & 26.6 & 24.8 & 0.9 & 0.81 & 0.09 & 0.56223 \\
e & Top tube & 25.4 & 24 & 0.7 & 0.63 & 0.07 & 0.54708 \\
\hline
\end{tabular}

Material used is Aluminium 6061 for the analysis, all dimensions are in millimetres ( $\mathrm{mm}$ )

diamond type bicycle frame with standard dimensions. For different frame geometries and cross-sections, the results might vary, which is a limitation of this research. Further studies can be conducted employing the findings of this research to improve rider comfort.

\section{Compliance with ethical standards}

Conflict of interest The authors declare that there is no conflict of interest with respect to the research, authorship, and/or publication of this article.

\section{References}

1. Ayachi FS, Dorey J, Guastavino C (2014) Identifying factors of bicycle comfort: an online survey with enthusiast cyclists. Appl Ergonom 46:124-136. https://doi.org/10.1016/j.aperg o.2014.07.010

2. Macdermid PW, Miller MC, Macdermid FM, Fink PW (2015) Tyre volume and pressure effects on impact attenuation during mountain bike riding. Shock Vib. https://doi. org/10.1155/2015/191075

3. Orendurff M (1996) The effect of mountain bicycle fork stiffness on impact acceleration. Oregon State University

4. Bambrick Y, Ngui M. The urban cycling survival guide: need-toknow skills and strategies for biking in the city. Toronto, Canada

5. Chiu MC, Wu HC, Tsai NT (2013) The relationship between handlebar and saddle heights on cycling comfort. Hum Interface Manag Inf 8016:12-19. https://doi.org/10.1007/978-3-64239209-2_2

6. Potter J, Sauer J, Weisshaar C, Thelen D, Ploeg HL (2008) Gender differences in bicycle saddle pressure distribution during seated cycling. Med Sci Sports Exerc 40:1126-1134. https://doi. org/10.1249/MSS.0b013e3181666eea

7. Rontescu C, Cicic DT, Amza CG, Chivu OR, Dobrota D (2015) Choosing the optimum material for making a bicycle frame. Metalurgija 54:679-682

8. Lin CC, Huang SJ, Liu CC (2017) Structural analysis and optimization of bicycle frame designs. Adv Mech Eng
9:168781401773951. https://doi.org/10.1177/168781401773951 3

9. Kennedy M, Lampe WN (2014) Applied ergonomics of cycling performance. In: Sport and exercise, 1st edn. Routledge, Abingdon, UK, pp 115-127

10. Soden PD, Millar MA, Adeyefa BA, Wonc YS (1986) Loads, stresses, and deflections in bicycle frames. J Strain Anal 21(4):185-195. https://doi.org/10.1243/03093247V214185

11. Wilson DG (2004) Bicycling science. MIT Press, Cambridge

12. Covill D, Begg S, Eddy E, Mark M, Morris R, Katz T (2014) Parametric finite element analysis of bicycle frame geometries. Procedia Eng 72:441-446. https://doi.org/10.1016/j.proeng.2014.06.077

13. Covill D, Blayden A, Coren D, Begg S (2015) Parametric finite element analysis of steel bicycle frames: the influence of tube selection on frame stiffness. Procedia Eng 112:34-39. https:// doi.org/10.1016/j.proeng.2015.07.172

14. Hartung T, Moechnig S; 2018 Oct. 2. Adjustable Compliant Bicycle. United States patent US 10,086,899

15. Bhandari VB (2017) Design of machine elements. McGraw Hill, Chennai

16. Howell LL (2001) Compliant mechanisms. Wiley, New York

17. Drouet JM, Champoux Y (2010) A novel dynamometric hubset design to measure wheel loads in road cycling. Procedia Eng 2:2925-2930. https://doi.org/10.1016/j.proeng.2010.04.089

18. Covill D, Allard P, Drouet JM, Emerson N (2016) An assessment of bicycle frame behaviour under various load conditions using numerical simulations. Procedia Eng 147:665-670. https://doi. org/10.1016/j.proeng.2016.06.269

19. Cheng YC, Lee CK, Tsai MT (2016) Multi-objective optimization of an on-road bicycle frame by uniform design and compromise programming. Adv Mech Eng 8(2):1-15. https://doi. org/10.1177/1687814016632985

20. Gere JM, Timoshenko SP (2004) Mechanics of materials. CBS Publishers \& Distributors, New Delhi

21. Umer A, Azmi A, Reyaz-Ur-Rahim RU (2018) Strength and stiffness optimization of diamond frame using corrugated tube. Technol Eng 15:11-15. https://doi.org/10.1515/teen-2018-0002

Publisher's Note Springer Nature remains neutral with regard to jurisdictional claims in published maps and institutional affiliations. 